\title{
Complete plastome sequencing resolves taxonomic relationships among species of Calligonum L. (Polygonaceae) in China
}

\author{
Feng Song ${ }^{1,2+}$, Ting $\mathrm{Li}^{1,3 \dagger}$, Kevin S. Burgess ${ }^{4}$ (D) Ying Feng ${ }^{2,5^{*}}$ (D) and Xue-Jun Ge ${ }^{3 *}$ (D)
}

\begin{abstract}
Background: Calligonum (Polygonaceae) is distributed from southern Europe through northern Africa to central Asia, and is typically found in arid, desert regions. Previous studies have revealed that standard DNA barcodes fail to discriminate Calligonum species. In this study, the complete plastid genomes (plastome) for 32 accessions of 21 Calligonum species is sequenced to not only generate the first complete plastome sequence for the genus Calligonum but to also 1) Assess the ability of the complete plastome sequence to discern species within the group, and 2) screen the plastome sequence for a cost-effective DNA barcode that can be used in future studies to resolve taxonomic relationships within the group.

Results: The whole plastomes of Calligonum species possess a typical quadripartite structure. The size of the Calligonum plastome is approximately 161 kilobase pairs (kbp), and encodes 113 genes, including 79 protein-coding genes, 30 tRNA genes, and four rRNA genes. Based on ML phylogenetic tree analyses, the complete plastome has higher species identification (78\%) than combinations of standard DNA barcodes (rbcL + matK + nrlTS, 56\%). Five newly screened gene regions ( $n d h F, \operatorname{trnS}-G$, $\operatorname{trnC}-p e t N$, ndhF-rp/32, rp/32-trnL) had high species resolution, where $n d h F$ and trnS-G were able to distinguish the highest proportion of Calligonum species (56\%).
\end{abstract}

Conclusions: The entire plastid genome was the most effective barcode for the genus Calligonum, although other gene regions showed great potential as taxon-specific barcodes for species identification in Calligonum.

Keywords: Calligonum, DNA barcodes, Plastid genome, Species resolution

\section{Background}

Calligonum L. (Calligoneae, Polygonaceae) are xerophytic shrubs distributed in Asia, Northern Africa, and southeastern Europe, although central Asia is the species diversification center for the genus. Many Calligonum species are the dominant species in desert vegetation, where they typically have reduced (or absent) leaves and

\footnotetext{
* Correspondence: luckfy@ms.xjb.ac.cn; xjge@scbg.ac.cn

${ }^{\dagger}$ Feng Song and Ting Li contributed equally to this work.

${ }^{2}$ State Key Laboratory of Desert and Oasis Ecology, Xinjiang Institute of

Ecology and Geography, Chinese Academy of Sciences, Urumqi 83011, China ${ }^{3}$ Key Laboratory of Plant Resources Conservation and Sustainable Utilization,

South China Botanical Garden, Chinese Academy of Sciences, Guangzhou 510650, China

Full list of author information is available at the end of the article
}

the young branches are the chief organs for photosynthesis [1]. Due to the extreme simplification of vegetative organs, species identification of the four sections in this genus is mostly based on fruit (achene) morphology; Calliphysa Borszcz., Calligonum, Pterococcus Borszcz., and Medusa Sosk. et Alexandr. are all typically characterized as having fruit that are membranous or saccate, with narrow wings or bristles at the margins, respectively [2-5]. Nevertheless, the fruit morphology can also be highly variable, making delimitation of species within the genus Calligonum troublesome [2]. The estimated number of species varies depending on the treatment: $28-80$ species [6]; 174 species reduced to 28 [5]; and 35 species [3].

\section{$\triangle B M C$}

C C The Author(s). 2020 Open Access This article is licensed under a Creative Commons Attribution 4.0 International License, which permits use, sharing, adaptation, distribution and reproduction in any medium or format, as long as you give appropriate credit to the original author(s) and the source, provide a link to the Creative Commons licence, and indicate if changes were made. The images or other third party material in this article are included in the article's Creative Commons licence, unless indicated otherwise in a credit line to the material. If material is not included in the article's Creative Commons licence and your intended use is not permitted by statutory regulation or exceeds the permitted use, you will need to obtain permission directly from the copyright holder. To view a copy of this licence, visit http://creativecommons.org/licenses/by/4.0/ The Creative Commons Public Domain Dedication waiver (http://creativecommons.org/publicdomain/zero/1.0/) applies to the data made available in this article, unless otherwise stated in a credit line to the data. 
To help with species identification, a number of molecular analyses have been implemented with little success in Calligonum. Although gene regions of the plastid genome (matK, rbcL, trnH-psbA), as well as the nuclear ribosomal internal transcribed spacer (nrITS) region, have been widely used as standard DNA barcodes for species identification in general [7-9], DNA barcoding analyses based on these standard regions, as well as other plastid DNA sequences ( $a t p B-r b c L, t r n L-t r n F, p s b K$ $p s b I$ ) fail to discriminate Calligonum species [10-12]. Furthermore, recent molecular sequence analysis [13] has treated five species (C. mongolicum, C. pumilum, C. chinense, C. alashanicum, and C. zaidamense) as a complex group, C. mongolicum. Given such discrepancies, more discerning genetic markers for the genus Calligonum are required to solve taxonomic confusion within the group.

The generation and utilization of a complete plastome sequence may be a possible solution to resolve taxonomic relationships in the genus Calligonum. Recently, complete plastid genomes have been suggested as a "super-barcode" to overcome the inherent limitations associated with traditional DNA barcoding [14-16]. A genetic sequence of the complete plastome can be easily obtained through a genome skimming approach of highcopy genomic targets, where its conserved gene content, organization and, structure makes it easy to assemble and annotate [17]. Notably, the compete plastome, in addition to all the standard plastid barcodes, should provide a wealth of informative and variable sites for the genetic identification and phylogenetic analyses of plant species [18, 19]: also see e.g., Ficus [20], Lilium [21], Panax [22], Stipa [23], Taxus [24], and Diospyros [25].

Once sequenced, the complete plastome sequence can be screened for potential taxon-specific, hyper-variable gene regions that are likely to be a more cost-effective, yet useful, species identification tool, than the entire plastome $[15,26]$. Although this strategy has worked for a number of gene regions across a range of taxa (i.e., the ycf1 gene region within Pterocarpus [27] and Prunus [28]; the trnC-rps16, trnS-trnG, and trnE-trnM gene regions for Panax [22]; and trnQ-psbK, trnR-atpA, trnS$p s b Z$ and rpl33-rps18 for Oresitrophe [26]) to date, there are no reported sequences for the plastomes of any Calligonum species, nor has a genome-wide search for taxon-specific barcodes been completed for the group.

To test the power and efficiency of plastome sequences to resolve taxonomic relationships within the genus Calligonum, we selected 32 accessions, representing 21 taxa of Calligonum, for genome skimming. We addressed the following three objectives: 1) Generate the complete plastome sequence for the genus Calligonum; 2) Assess the ability of the complete plastome sequence to discern species within the group, and 3) Screen the plastome sequence for a cost-effective barcode that can be used in future studies to resolve taxonomic relationships within the group.

\section{Results \\ Plastome analysis}

Complete plastomes from 32 accessions of Calligonum were submitted to GenBank (Table 1). Plastome size ranged from 161,184 bp (C. rubicundum) to $162,535 \mathrm{bp}$ (C. jeminaicum). The Calligonum plastomes were highly conserved in organization and structure. They showed a typical quadripartite genome organization, including a LSC (Large Single Copy) region (86,766-88,160 bp) and a SSC (Small Single Copy) region (13,286-13,416 bp), which were separated by two IR (Inverted Repeat) regions (30,468-30,552 bp) (Table 1, Fig. 1). The total GC content was $37.50 \%$ in the plastomes of Calligonum (Table 1), whereas the GC content was higher in the IR region $(41.30 \%)$ than in the LSC (35.60-35.70\%), and SSC (32.40-32.70\%) regions.

All plastomes encoded 113 unigenes, including 79 protein-coding genes, 30 tRNA genes, and four rRNA genes with identical gene order (Table 1, Fig. 1). None of the regions were inferred to be pseudogenes (Additional file 1: Table S1). Among these genes, five complete protein-coding genes $(r p l 2, r p l 23, y c f 2, n d h B$, $r p s 7, y c f 1$ ); three partial protein-coding genes (rps19, rps12, ndhF), seven tRNA genes $\left(\operatorname{trn} M^{C A U}, \operatorname{trnL} L^{C A A}\right.$, $\left.\operatorname{trn} V^{G A C}, \operatorname{trn} I^{G A U}, \operatorname{trn} A^{U G C}, \operatorname{trn}^{A C G}, \operatorname{trn} N^{G U U}\right)$ and four rRNA genes $(r r n 16, r r n 23, r r n 4.5, r r n 5)$ were duplicated in the IR regions (Fig. 1).

Using $C$. jeminaicum as the reference, the homology of 21 Calligonum species was investigated to determine the level of sequence divergence (Additional file 2: Figure S1). The complete plastome alignment for the 21 Calligonum species showed that there were no rearrangement events among Calligonum species (Additional file 5: Figure S3). The plastome sequences were highly similar within the genus Calligonum. The $\mathrm{LSC} / \mathrm{IRb}$ and IRb/SSC borders in the Calligonum plastome were positioned within the coding region of rps 19 (with 107-108 bp located at IRb) and $n d h F$ (with 19-95 bp located at IRb) genes, respectively (Fig. 2). The intergenic rps15-ycf1 was located in the border of SSC/IRa, whereas the intergenic rpl2-trnH $H^{G U G}$ was located in the border of IRa/LSC in Calligonum (Fig. 2). There was a slight variation in genome size and IR expansion / contraction (Fig. 2, Additional file 2: Figure S1). Observed plastome length variation was caused by two inserts in C. jeminaicum (Additional file 2: Figure S1), which were located in the LSC; one (segment I: about $800 \mathrm{bp}$ ) in the intergenic region rps16-trn $Q^{U U G}$, and another (segment II: about $400 \mathrm{bp}$ ) in the intergenic region pet $N$-psbM (see details Additional file 2: Figure S1 and Additional file 4: Table S2). 


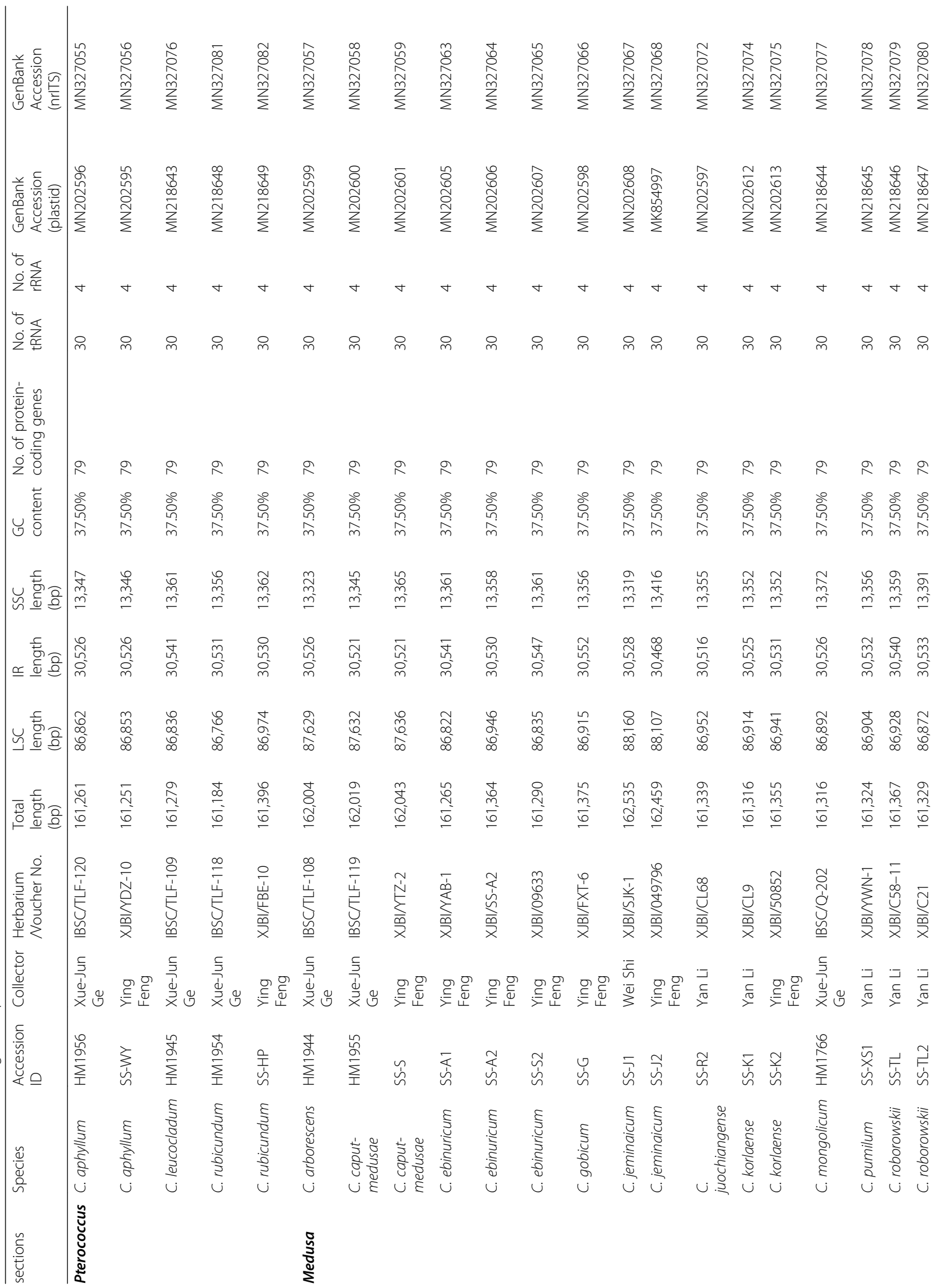




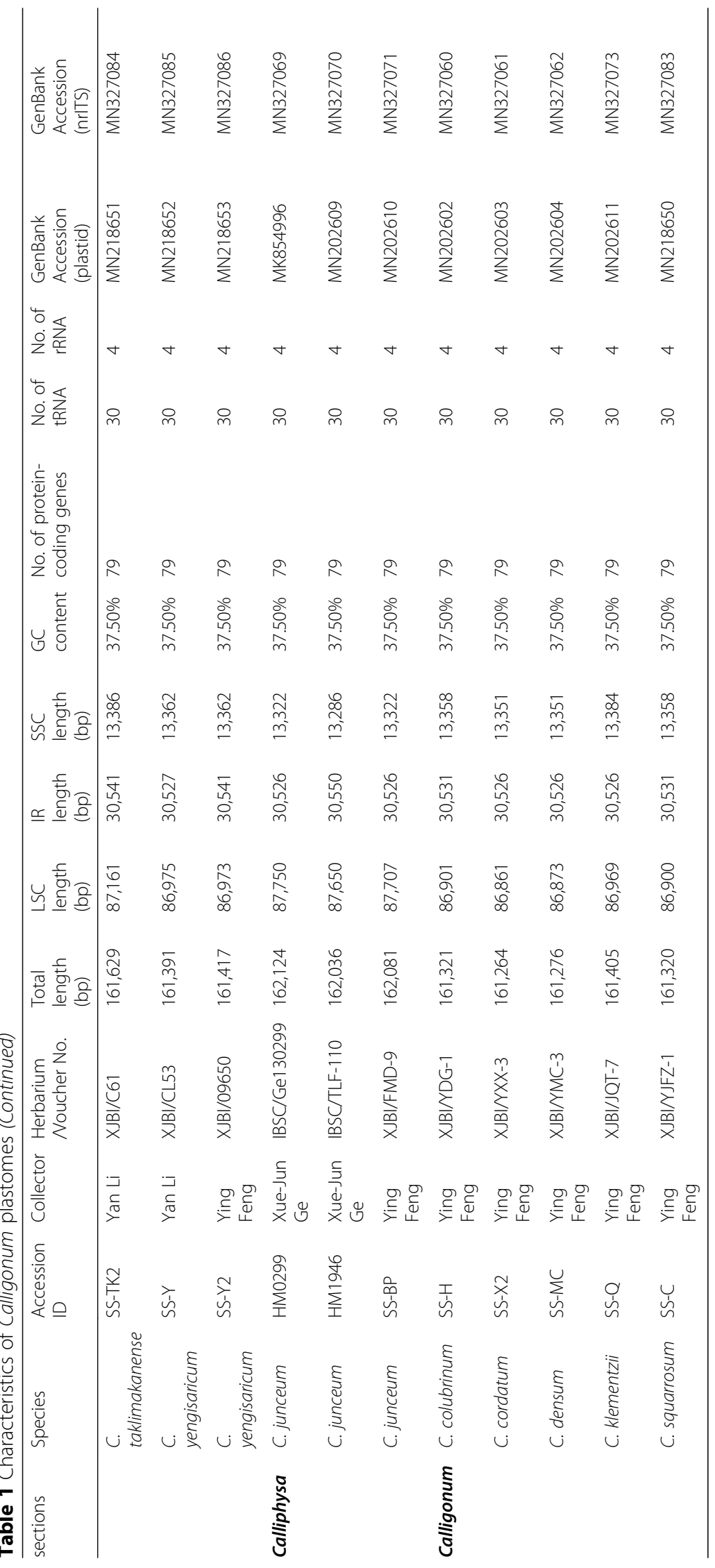




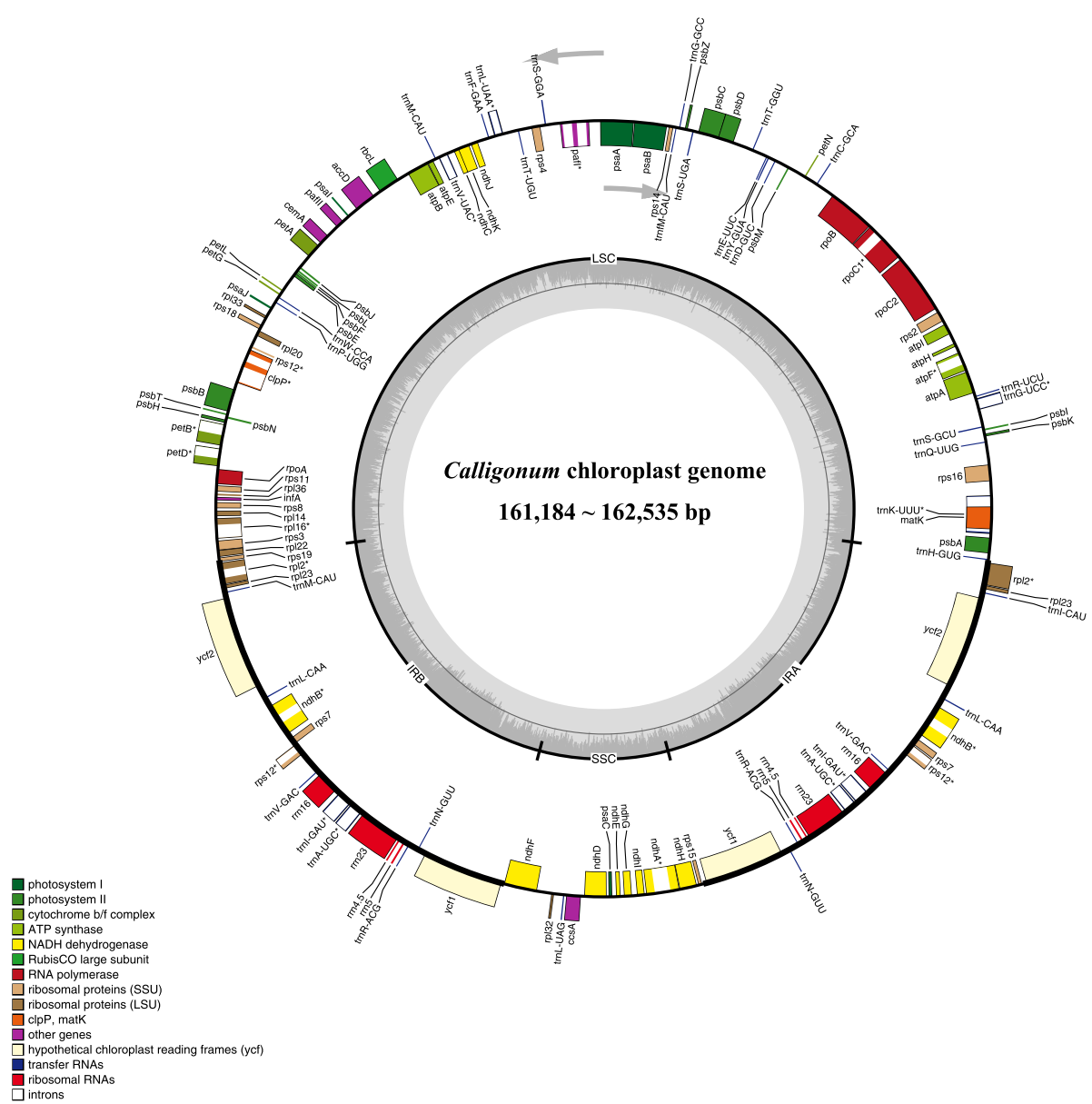

Fig. 1 Gene map of the complete chloroplast genome of Calligonum. Arrows indicate the direction of transcription: genes located outside the outer circle are transcribed in the counter-clockwise direction, those inside are transcribed in the clockwise direction. Color codes represent different functional gene groups. Inside the middle circle, GC and AT content variations are indicated by darker and lighter gray, respectively

To estimate selection pressure, the rate of nonsynonymous $(d N)$ and synonymous $(d S)$ substitutions, as well as the $d N / d S(\omega)$ ratio, was determined for 79 proteincoding genes (Additional file 7: Figure S4). In most genes, $d S$ were higher than $d N$. The $d N$ and $d S$ values were 0 to 0.17 , and 0 to 0.63 , respectively. Most genes showed $\omega$ ratios less than 0.5 , and four genes (psbI, pet $N$, $p s b E$, and $p s b L$ ) had the lowest (close to 0) $\omega$ ratios (Additional file 7: Figure S4). The $\omega$ ratios of rpl23, ycf1, and $y c f 2$, ranged from 0.5 to 1 .

\section{Whole plastome for discriminating Calligonum}

A total 1151 polymorphic sites $(0.86 \%)$ were detected in the $133,980 \mathrm{bp}$ matrix of 32 Calligonum accessions (Table 2). Sequence divergences among 32 Calligonum plastomes were compared using nucleotide differences and sequence distances. At the interspecific level, the greatest differentiation occurred between C. taklimakanense and $C$. jeminaicum (p-distance $=3.69 \times 10^{-3}$, different sites $=2867$ ), whereas the closest species were $C$. colubrinum and C. squarrosum (p-distance $=0$, nucleotide differences is 1) (Additional file 6). At the intraspecific level, the p-distances ranged from $0.2 \times 10^{-4}(C$. aphyllum) to $8.5 \times 10^{-4}$ (C. roborowskii), and the number of different sites ranged from 14 (C. aphyllum) to 388 (C. roborowskii) (Additional file 6).

Based on the plastomic matrix, identical ML and BI trees were obtained (Fig. 3). The monophyly of the genus Calligonum was strongly supported in both cases. The infrageneric phylogeny was well resolved and most nodes were strongly supported (Fig. 3). Only two nodes, one that includes C. colubrinum, C. squarrosum and $C$. rubicundum $(\mathrm{BS}=40 \%, \mathrm{PP}=0.96)$, and another that includes C. ebinuricum, C. leucocladum, and C. gobicum (BS $=59 \%, P P=0.97)$, were not well supported. The discriminatory power of the plastomes was assessed by investigating the monophyly, and branch support recovered in those species where multiple accessions were sampled. Seven of the nine species (78\%) that had more than one accession were resolved as reciprocally 


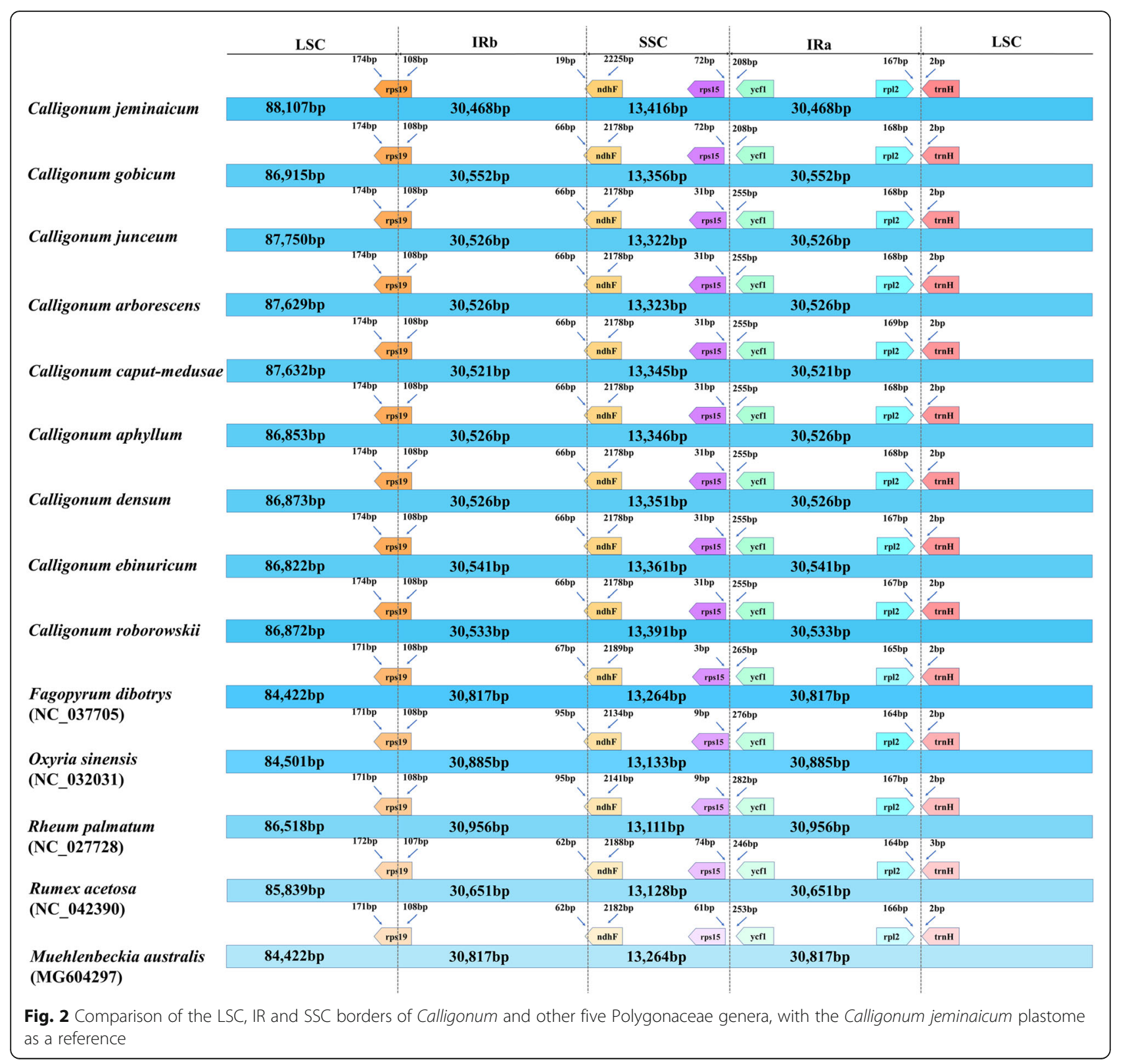

monophyletic except for C. ebinuricum and C. rubicundum (Fig. 3). The relationship among samples that had one accession was well supported (BS $>93 \%$, PP $>0.98$ ), only C. gobicum $(\mathrm{BS}=59 \%, \mathrm{PP}=0.97)$ was the exception (Fig. 3).

The phylogenetic tree did not support the division of three or four sections in Calligonum [5, 29]. Only sect. Calliphysa, containing one species (C. junceum), was well supported $(\mathrm{BS}=100 \%, \mathrm{PP}=1.00)$. Species from the other sections often formed one clade. For example, C. aphyllum from sect. Pterococcus formed one well supported $(\mathrm{BS}=100 \%, \mathrm{PP}=1.00)$ clade with C. densum and C. cordatum, both of which are from sect. Calligonum.

\section{Analyses of potential barcodes}

Due to the PCR failure for ITS [12], we de novo assembled nrITS from genome skimming data, which included the ITS1, 5.8S, and ITS2 regions. Alignments and concatenation of 32 nrITS sequences yielded a $768 \mathrm{bp}$ matrix in length, including 22 polymorphic sites $(2.92 \%)$ (Table 2). The discriminatory power analysis based on the BI method exhibited weak resolution at most nodes. For nine species with multiple accessions, only C. ebinuricum was recovered as a supported monophyletic clade ( $\mathrm{PP}=0.86$, Fig. $5 \mathrm{a}$ ), with an $11 \%$ success rate. ITS2 (15 polymorphic sites) harbors more variability than ITS1 (5 polymorphic sites), and revealed higher discrimination power (Table 2). 
Table 2 Discrimination ability of standard and species-specific barcodes and their combinations

\begin{tabular}{|c|c|c|c|c|c|c|}
\hline \multicolumn{3}{|l|}{ DNA barcodes type } & \multirow{2}{*}{$\begin{array}{l}\text { length } \\
\text { (bp) } \\
449\end{array}$} & \multirow{2}{*}{$\begin{array}{l}\text { Polymorphic } \\
\text { sites } \\
6\end{array}$} & \multirow{2}{*}{$\begin{array}{l}\text { Polymorphic sites } \\
(\%) \\
1.34\end{array}$} & \multirow{2}{*}{$\begin{array}{l}\text { Identified species (Success } \\
\text { rate) } \\
0(0 \%)\end{array}$} \\
\hline Standard DNA & nrlTs & $\mathrm{ITS} 1+5.8 \mathrm{~S}$ & & & & \\
\hline & & $5.8 S+1 T S 2$ & 467 & 16 & 3.43 & $1(11 \%)$ \\
\hline & & nrlTs & 768 & 22 & 2.92 & $1(11 \%)$ \\
\hline & plastid & matK & 1527 & 14 & 0.92 & $2(22 \%)$ \\
\hline & & $r b c L$ & 1428 & 8 & 0.56 & $2(22 \%)$ \\
\hline & & $\operatorname{trnH}-p s b A$ & 386 & 23 & 5.96 & $2(22 \%)$ \\
\hline & combination & $m a t K+r b c L$ & 2955 & 22 & 0.74 & $3(33 \%)$ \\
\hline & & $\operatorname{trnH}-p s b A+m a t K+r b c L$ & 3341 & 44 & 1.32 & $3(33 \%)$ \\
\hline & & matK $+r b c L+$ nrlTS & 3723 & 44 & 1.18 & $5(56 \%)$ \\
\hline & & $\begin{array}{l}\operatorname{trnH}-p s b A+\text { matK }+ \\
r b c L+\text { nrlTS }\end{array}$ & 4109 & 66 & 1.61 & $4(44 \%)$ \\
\hline \multirow[t]{9}{*}{ Genomic element } & $\operatorname{trn} E-T$ & & 995 & 21 & 2.11 & $1(11 \%)$ \\
\hline & $\operatorname{trn} T-L$ & & 1026 & 36 & 3.51 & $2(22 \%)$ \\
\hline & \multirow{6}{*}{$\begin{array}{l}\text { potential specific- } \\
\text { barcodes }\end{array}$} & $n d h F$ & 2244 & 38 & 1.69 & $5(56 \%)$ \\
\hline & & ndhF-rp/32 & 993 & 28 & 2.82 & $4(44 \%)$ \\
\hline & & rp/32-trnL & 632 & 16 & 2.53 & $4(44 \%)$ \\
\hline & & $\operatorname{trn} C-p e t N$ & 900 & 82 & 9.11 & $4(44 \%)$ \\
\hline & & $\operatorname{trnS}-G$ & 1233 & 26 & 2.11 & $5(56 \%)$ \\
\hline & & Combination* & 5795 & 200 & 3.45 & $6(67 \%)$ \\
\hline & \multicolumn{2}{|c|}{ Complete plastid genomes (only one IR) } & 133,980 & 1151 & 0.86 & $7(78 \%)$ \\
\hline
\end{tabular}

For the three standard plastid barcodes, complete matK, $r b c L$ and trnH-psbA sequences had the same resolution power $(22 \%)$. However, the combinations of $m a t K+r b c L$ and that of trnH-psbA+matK+rbcL slightly increased identification power to $33 \%$ (Table 2, Additional file 9: Figure S6C-G). When the plastid barcodes were combined with nrITS, the identification rate increased to $44(t r n H-p s b A+m a t K+r b c L+$ nrITS $)$ and $56 \%(m a t K+r b c L+$ nrITS) (Table 2, Fig. 5b, Additional file 9: Figure $\mathrm{S} 6 \mathrm{H})$. Both combinations generated tree topologies that were similar to the complete plastome data sets, although their resolution power was lower than that of the plastid genomes (Table 2).

In this study, the variability of additional, potential plastid regions was quantified with nucleotide diversity (Pi), which was calculated with a sliding window (window length $=1000 \mathrm{bp}$ and step size $=300 \mathrm{bp}$ ). The values of nucleotide diversity (Pi) ranged from 0 to 0.0059 . Seven hyper-variable regions $(\mathrm{Pi}>0.003)$ in these genomes were identified, six of which are intergenic regions (i.e., trnS-G, trnC-petN, trnE-T, trnT-L, $n d h F-$ rpl32, and rpl32-trnL). Only one protein-coding region ( $n d h F$, Fig. 4) showed high nucleotide diversity within Calligonum. These hyper-variable regions were all located in the LSC and SSC regions (Fig. 4). The polymorphic site number in these seven regions was remarkably higher than that in standard DNA barcodes
(rbcL, matK, trnH-psbA, nrITS) (Table 2). Their power as potential taxon-specific barcodes was tested through a tree-based method. The species discrimination rates (range from 44 to $56 \%$, Table 2, Fig. 5) were much higher than that of $r b c L$ and $m a t K$, except the $\operatorname{trn} T-L$ (discrimination rate of $22 \%$, Table 2) and $t r n E-T$ regions (discrimination rate of $11 \%$, Table 2). Among these five regions, $n d h F$ and trnS-G had the highest discrimination rate $(56 \%)$ (Table 2, Fig. $5 \mathrm{~d}-\mathrm{e})$. The combination of the five gene regions ( $n d h F, \operatorname{trnS}-G, \operatorname{trnC}-$ pet $N$, $n d h F-r p l 32$, rpl32-trnL) increased the identification of species to $67 \%$ (Table 2, Fig. 5h).

\section{Discussion}

\section{Plastome features}

In this study, we generated 32 complete Calligonum plastomes. The plastomes in Calligonum are highly conserved and ranged in size of 161,184 to $162,535 \mathrm{bp}$. When compared to the plastomes of the other Polygonaceae genera (e.g., Fagopyrum [30], Rumex [31], Oxyria [32]), all the plastomes generated in this study exhibited typical plastome structure, gene order and content (Fig. 1). In addition, the GC content of Calligonum (37.50\%) was similar to that of Fagopyrum (37.80-38.0\%) [30], Rumex acetosa (37.20\%) [31], and equal to that of Oxyria sinensis (37.50\%) [32]. Inverted repeat (IR) contraction and expansion is a common evolutionary phenomenon 


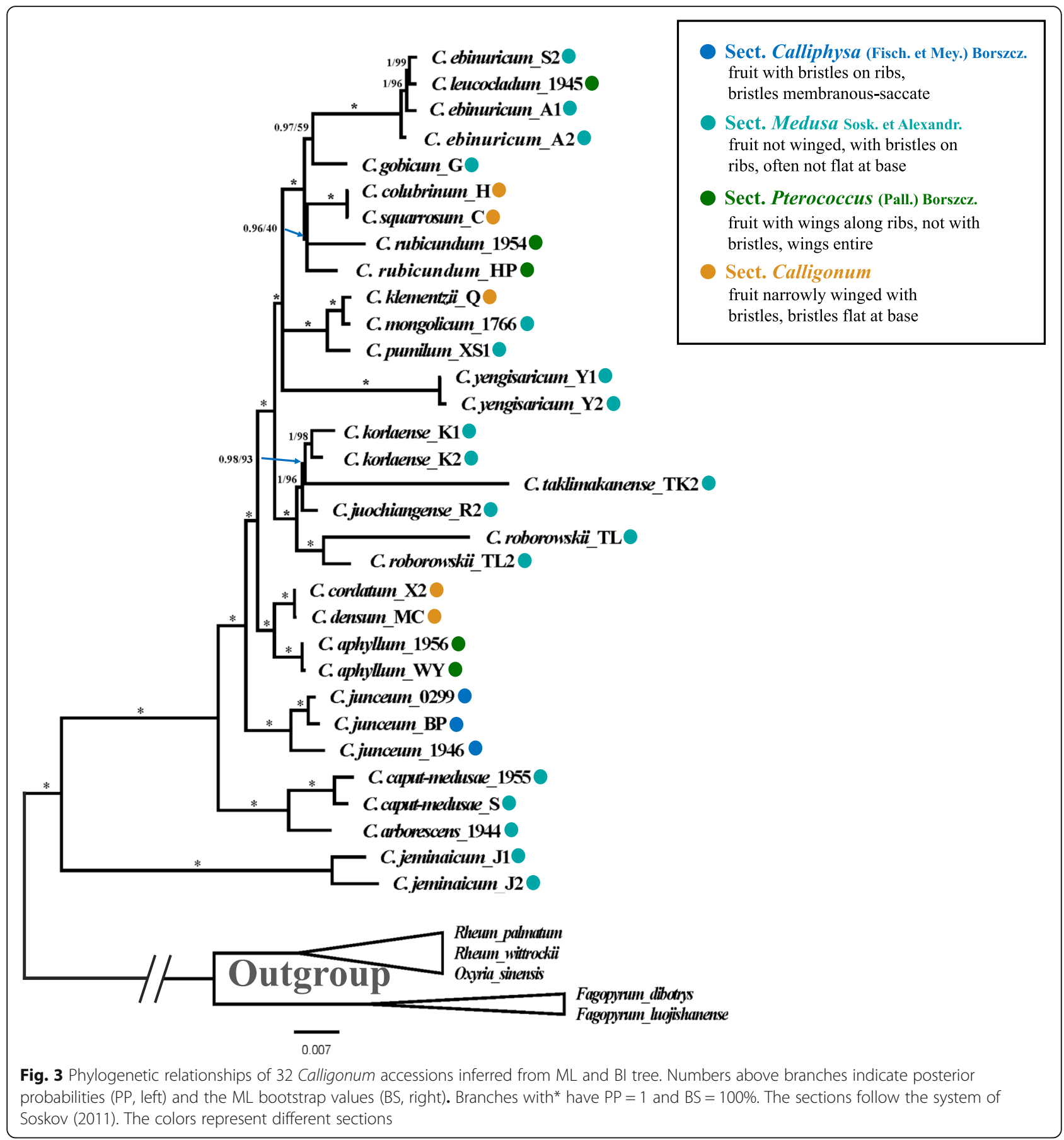

and may cause variation in plastome length [33]. Nonetheless, the IR regions of the Calligonum plastomes varied slightly from $30,468 \mathrm{bp}$ to $30,552 \mathrm{bp}$ (Fig. 2). Compared to other Polygonaceae genera that have plastome data in GenBank, the IR region in Calligonum is more conserved than the Large Single Copy (LSC) and Small Single Copy (SSC) regions, where most differences were observed in the intergenic and intron regions (Additional file 3: Figure S2). One of the two inserts (segment I) found in $C$. jeminaicum also existed in Muehlenbeckia australis, Oxyria sinensis, and Rheum palmatum, whereas it was absent in Fagopyrum, Rumex and Calligonum (except $C$. jeminaicum, C. junceum, $C$. arborescens, and C. caput-medusae, Additional files 2, 3: Figure S1, S2). The other insert (segment II) was only absent in Calligonum (except C. jeminaicum). Collectively, these results indicate that intergenic and intron variation are a significant source of length variation in 


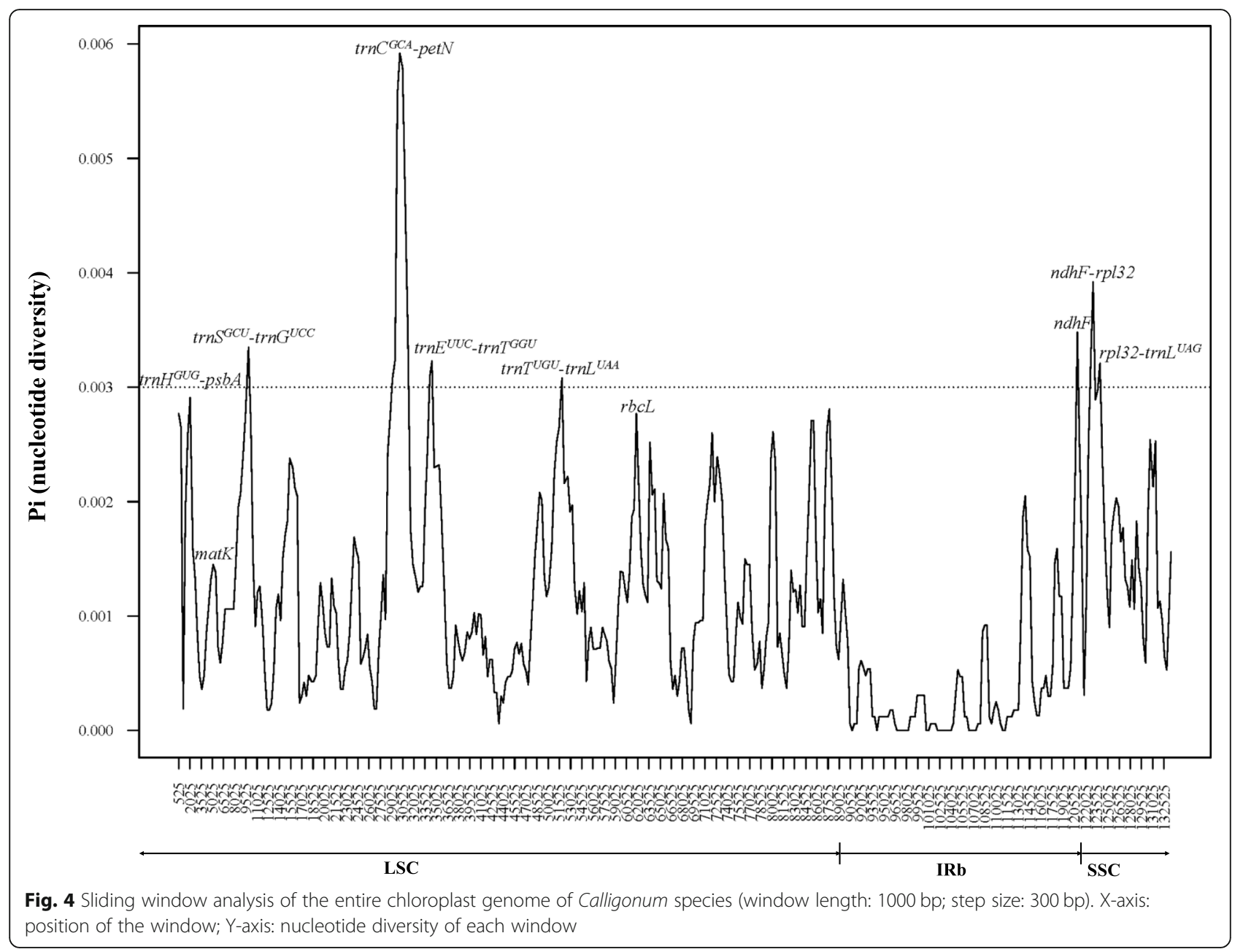

Calligonum, compared to other genera in the Polygonaceae (Fig. 2, Additional file 3: Figure S2).

\section{Taxonomic resolution based on the complete plastome}

Complete plastomes have been suggested as having the potential to increase species resolution among plant species $[18,19]$, and have been used to discriminate species in a number of taxa that are difficult to resolve (e.g., Ficus [20]; Panax [22]; Taxus [24]; Diospyros [25]). In our study, seven of the nine species $(78 \%$, Table 2$)$ in Calligonum that have more than one accession, were correctly identified to species. Among the seven species, C. roborowskii revealed the highest intraspecific variation (388 variable sites), where two individuals showed obvious branch length difference (Fig. 3). Previous studies have revealed high genetic variation among populations of C. roborowskii (AMOVA: 91.19\%, Gst: 0.818) that also have significant phylogeographical structure based on cpDNA data [34]. In our study, we also found that those species with a single accession were well resolved with strongly supported nodes in our phylogenic tree (Fig. 3). The wide distribution range, patchiness of populations and short-distance seed dispersal due to gravity, all likely contribute to genetic differentiation in C. roborowskii [34]. Collectively, these results indicate that the complete plastome sequence is an effective tool for species discrimination in Calligonum and are in-line with current taxonomic treatments. For example, in the Flora of China [3], C. juochiangense was reduced as a synonym of C. pumilum, however, based on further morphological analysis, Feng et al. [35] found that both species are quite different from each other and that they should be considered as two independent species. Based on our plastome phylogeny (Fig. 3), C. juochiangense formed one clade with $C$. korlaense and C. taklimakanense with strong support, and separate from C. pumilum. Our plastome results support their entities as separate species taxonomy. Although C. colubrinum and C. squarrosum were treated as different species in the Flora of China [3], they have very similar morphological characters, but differ in fruit size, color and location of bristles on achenes. However, these characters may change at the different development stages, and there is no discontinuous variation between these two species. There is a 


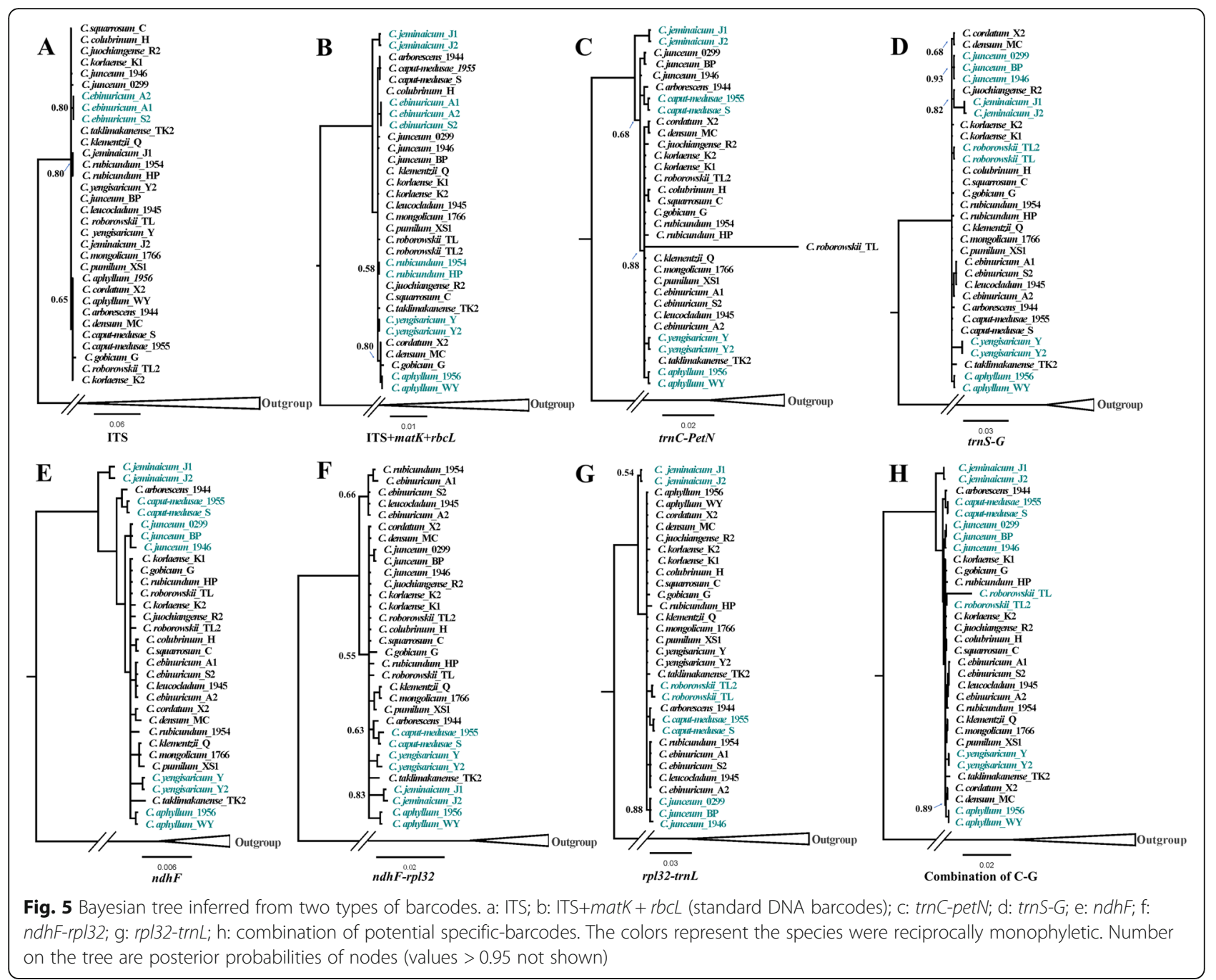

single nucleotide site difference between the plastome of C. colubrinum and C. squarrosum, which suggests they are indeed the same species and C. squarrosum $\mathrm{N}$. Pavlov (1933) should be treated as a synonym of C. colubrinum E. Borszcow (1860).

Although our sampling only covered 21 species in Calligonum, these species represented all the sections in the classifications of Calligonum [5](Fig. 3, Additional file 8: Figure S5), with the exception of the species from North Africa and East Mediterranean due to the sampling difficulty. The plastome data presented in this study provide further delineation of taxa within the group. For example, neither infrageneric classification of the genus Calligonum [5, 29] was supported in this study (Fig. 3, Additional file 8: Figure S5). Furthermore, our results are in contrast with the most recent taxonomic treatment of Calligonum, Sosk. [5], which delineates 28 species and many of which have been reduced to synonyms: C. gobicum, C. korlaense, C. yengisaricum, and C. roborowskii have been reduced to the synonym of $C$. litwinowii Drob.; and C. pumilum and C. jeminaicum to that of $C$. rubescens. Although in our study the polymorphic site ratio is relatively low for the complete plastome $(0.86 \%)$, the total number of polymorphic sites (1151) is relatively high, indicating that complete plastomes are likely an effective tool for solving taxonomic issues within this group of taxa, especially in genera that have many closely related species (i.e., those that have experienced recent speciation).

Although the Calligonum plastome showed relatively high species resolution in this study, approximately $20 \%$ of the species could not be successfully identified. Calligonum species are known to interbreed in sympatry [13, $34,36]$, and it seems likely that in particular, interspecific hybridization may have caused the lack of resolution for C. ebinuricum and C. rubicundum. For example, three C. ebinuricum accessions formed one clade with $C$. leucocladum (BS $=100 \%, P P=1.00$ ), however, $C$. ebinuricum alone formed a monophyletic clade, with strong support, in the nrITS phylogeny. Hybridization or 
introgression has been suggested as the reason for conflicting phylogenic patterns between paternally inherited nuclear genes and maternally inherited plastid genes [37, 38], and thus provides a plausible reason why C. leucocladum shares its plastome sequence with C. ebinuricum. Similarly, C. rubicundum accessions formed a single clade with $C$. colubrinum and $C$. squarrosum $(\mathrm{BS}=40 \%, \mathrm{PP}=0.96)$, which are of known hybrid origin [5]. The fact that both C. ebinuricum and C. rubicundum were sampled from cultivated plants at Turpan Eremophytes Botanical Garden not only highlights the possibility that introgression among closely related species in ex situ plant collections is possible [39], but also serves as a caution, that in some cases, utilizing such collections to test species resolution may be a problem.

\section{Screening the entire plastome for potential DNA barcodes}

When screening the complete plastome sequence of Calligonum to find suitable barcode regions to identify species in the genus, we first assessed species resolution for a suite of standard DNA barcodes that have been used to assess species resolution in other taxa. In our study, on average, species resolution was low for all the standard DNA barcodes that were screened. In addition, the complete matK, rbcL, trnH-psbA intergenic region, and nrITS sequences were successfully retrieved from the genome skimming data. As a single barcode, species resolution of these gene regions was very low, which ranged from $11 \%$ (ITS) to $22 \%$ (rbcL, matK, trnH-psbA). Their combination slightly increased species resolution from $33 \%(r b c L+$ matK $), 33 \%(r b c L+$ matK + trn $H-p s b A)$ to $55 \%(r b c L+m a t K+$ ITS) (Table 2). These results verified those of previous studies that also showed relatively low resolution rates $[12,36]$, even though we were able to sequence and screen longer segments (i.e., the complete gene region) of the standard DNA barcodes. There are three possible reasons for the high rates of species identification failure for these DNA barcodes in Calligonum: 1) the current taxonomy for the genus is inaccurate; 2) past hybridization events have blurred species boundaries; and 3) recent speciation events have resulted in coalescent failure of the plastid genome [13, $34,38,40]$. Although the number of recognized species for Calligonum varies among monographs $[3,5]$, the genus is thought to have undergone recent and rapid diversification in the arid deserts of Western Central Asia [41, 42], which may contribute the failure of DNA barcoding to discriminate among Calligonum species.

As a biparental inherited marker, nrITS (or ITS2) usually reveals higher species resolution than plastid DNA barcodes [9, 43]. However, nrITS was highly conservative in Calligonum, having relatively few polymorphic sites $(22,2.92 \%$ of the gene region). As a result, species resolution of nrITS (11\%) was even less than the three plastid standard barcodes combined. This result may be due to the young age of this genus [41, 42], frequent hybridization [13] and/or introgression, where most hybridization events in Calligonum have been documented between relatively young species that have diverged since the Quaternary [5]. For example, experimental interspecific hybridization among predominantly self-incompatible taxa from sect. Medusa showed high fruit sets suggesting no genetically based reproductive barrier [13]. In addition, to these three plausible biological processes, the nrITS consensus sequence in our study was retrieved and assembled based on a seed-andextend strategy using genome skimming data. This alignment algorithm retrieves the alleles in relatively high frequency, and thus may underestimate the number of polymorphic sites associated with our study species [44] (see Additional file 10, Additional file 11: Table S3). Collectively, these results suggest that nrITS is unable to discern among most Calligonum species, and this constraint should be considered in future studies.

\section{Screening of additional potential barcode regions}

DNA barcoding for plants, in general, remains a challenge and, due to the lack of genetic variation for standard barcode gene regions, it is common that closely related, congeneric species share similar barcodes $[15$, 45-48]. For example, molecular analyses using standard DNA barcodes have failed to differentiate species in Solanum sect. Petota (wild potatoes) [49], Salix [45], Curcuma [50], and Euphrasia [16], to name a few. Lineage-specific (or taxon-specific) barcodes, however, may enhance species discrimination rates because they typically provide more genetic information within a particular group of species compared to the use of standard DNA barcodes typically used across taxa of broad phylogenetic dispersion. In addition, and compared to complete plastome sequencing, the use of taxon-specific barcode regions are certainly more cost-effective for the large-scale assessment of species-rich genera [15]. In this study, among the new regions that we screened for Callignoum, five (ndhF, trnS-G, trnC-petN, ndhF-rpl32, rpl32-trnL) had species resolution rates that ranged from 44 to $56 \%$ (Table 2), which is comparable to results found in Quercus [51], Diospyros [25], and Panax [22]. Among these regions, $n d h F$ and $t r n S-G$ had the highest species discrimination (56\%), and in combination (67\%) (Table 2), for our study taxa. When considering the cost and time associated with complete plastome sequencing, it is likely that these gene regions have great potential as a Calligonum-specific barcode in future studies.

Rapid and cost-effective development of highthroughput sequencing technology has allowed for a rapid increase in the number of complete plastomes 
available on GenBank (4692 plant species as Feb. 21, 2020; https://www.ncbi.nlm.nih.gov/genome/organelle/). Although complete plastome sequencing is a heavy burden for many laboratories, our contribution to this increasing dataset will make it easier to find taxon-specific barcodes based on plastome data. For those genera lacking plastome data at GenBank, we suggest the sequencing of a few species, at relatively low cost, to establish plastome sequences that can then be screened for taxonspecific barcodes. We suspect that in the future, the plastome will be widely applied as "the plant barcode 2.0 " in many related fields $[19,52]$. For those genera or species complex with rapid radiation or frequent hybridization, we also suggest that future barcoding studies couple plastome screening with targeted enrichment methods $[19,52]$ that sample the wealth of genetic resources stored, yet relatively untapped, in the nuclear genome.

\section{Conclusions}

The use of standard DNA barcodes for species identification in Calligonum is insufficient. In this study, we tested whole plastomes, standard DNA barcodes and hyper-variable, taxon-specific regions for rates of species resolution in the genus. Among these genetic tools, complete plastomes greatly improved species resolution in Calligonum and a number of gene regions showed high potential to be used as taxon-specific barcodes in future studies.

\section{Methods}

\section{Taxon sampling and DNA sequencing}

In total, 32 samples representing 21 species of Calligonum $[5,53]$ were collected from northwestern China (Table 1); only three species in China were not included in this study. No specific permissions were required for the relevant locations/activities. Among the 21 species, nine species had more than one individual sampled. The nomenclature system for this study follows the Flora Reipublicae Popularis Sinicae (FRPS) [54] and the Flora of China (FOC) [3]. Voucher specimens were deposited in the Herbarium of the Xinjiang Institute of Ecology and Geography, Chinese Academy of Sciences (XJBI) and the Herbarium of South China Botanical Garden (IBSC).

Total genomic DNA was extracted from approximately $100 \mathrm{mg}$ of silica-dried branch material. Isolation protocols followed the cetyltrimethyl ammonium bromide (CTAB) method [55]. DNA extracts were fragmented for $300 \mathrm{bp}$ short-insert library construction and sequenced $-2 \times 150$ bp paired-end (PE) reads on an Illumina HiSeq $\mathrm{X}$-Ten instrument at the Beijing Genomics Institute (BGI, Shenzhen, China). The raw reads were assessed by FastQC 0.11.5 (http://www.bioinformatics.babraham.ac. $\mathrm{uk} /$ projects/fastqc/) and edited using Trimmomatic 0.35 [56] to remove adapters and low-quality bases. After removing low quality reads and adaptor sequences, an 3.0 G bp paired-end clean read was obtained for each sample.

\section{Plastome and nrDNA assembly and annotation}

The clean data were assembled using NOVOPlasty v1.1 [57], with a reference genome of Fagopyrum tataricum (Polygonaceae) (GenBank accession no. NC_027161). Clean reads were then re-mapped to the preliminary genome and the complete plastid genome sequences were adjusted using Bowtie 2 v2.3.4.1 [58] and SAMtools v1.9 [59]. The finished plastid genomes were annotated with DOGMA [60], and GeSeq [61], then adjusted manually using Geneious v 11.0.2 [62]. Gene start and stop codons were determined by comparison to the genome of F. tataricum. Finally, the annotated plastid genomes were submitted to GenBank (Table 1) and Organellar Genome Draw [63] was used to illustrate a circular genome map.

Two steps were adopted to complete nrITS sequence reconstruction. Firstly, the nuclear ribosomal (nr) ITS sequence of G. junceum (GenBank accession no. AB542774) was used as the reference to assemble the entire nrITS sequence (ITS1, 5.8S, and ITS2). Sequence assembly followed the same procedures described above. Each assembled sequence served as a reference sequence for the next steps. Secondly, clean reads were mapped to the new obtained reference using Bowtie 2 v2.3.4.1 [58] and SAMtools v1.9 [59], resulting in a BAM file with only mapped reads. The BAM file was then imported into Geneious V. 11.0.2 [62] and consensus sequences were extracted with default settings. Each consensus sequence served as the final nrITS sequence and was annotated by comparison to the reference sequence and then submitted to GenBank (Table 1).

\section{Variation analyses}

To illustrate interspecific sequence variation and gene organization of the entire plastid sequences among each of the 21 species, we used mVISTA software with the LAGAN model [64]. The alignments, with annotations, were visualized using $C$. jeminaicum as a reference, which was generated in the present study. Mauve v1.1.1 (a plugin within Geneious v 11.0.2) [65] was used for alignment and for the detection of gene rearrangements and inversions among Calligonum taxa. Sliding window analysis (DnaSP v6 [66]) was conducted to generate Pi values of the plastid genomes. Evolutionary divergence (nucleotide differences and p-distances) among the 32 accessions were evaluated using MEGA X [67]. Hypervariable regions were defined as a region with relatively high nucleotide diversity $(\mathrm{Pi})$ and high species resolution. 
The step size was set to $300 \mathrm{bp}$, with a $1000 \mathrm{bp}$ window length, and regions with the $\mathrm{Pi}$ value $>0.003$ (more than half of the maximum) were extracted to assess species resolution (see Discriminatory power analysis described below).

To detect whether plastid genes were under selection pressure, the ratio of nonsynonymous $(d N)$, synonymous $(d S)$ and $\omega(d N / d S)$ values of each protein coding gene in the Calligonum plastid genomes were analyzed using CodeML in PAML Version 4.9d [68] with a One-ratio model $($ model $=0$, seqtype $=1$, NSsites $=0)$. Positive selection is detected if the value of $d S$, summed over all branches on the tree, is $>0.5$ (PAML FAQ, http://saf.bio. caltech.edu/saf_manuals/pamlFAQs.pdf).

\section{Discriminatory power analysis}

A tree-based method was used to investigate the power and efficiency of plastome sequences for species identification. The discriminatory power was assessed by monophyly and the branch support recovered in those species with multiple accessions. The DNA sequences for the complete plastid genomes (after removing one inverted repeat), and potential DNA barcode regions, were aligned using the default option implemented in MAFFT version 7 [69]. The most appropriate model of nucleotide substitution for each nucleotide sequences was determined by the Akaike Information Criterion (AIC) in jModeltest $\mathrm{v}$ 2.1.10 [70]; results are listed in Additional file 12: Table S4. Bayesian inference (BI) was performed using MrBayes 3.2.6 [71] with Markov chain Monte Carlo simulations algorithm (MCMC) for $1 \times 10^{6}$ generations with four incrementally-heated chains. Each matrix was given its own optimal model (Additional file 12: Table S4). Maximum likelihood (ML) trees were generated in RAxML 8.2.10 [72] with 1000 replicates. The trees were viewed and edited with FigTree v1.4.3 (http://github.com/rambaut/figtree/). In all analyses, the five Polygonaceae species were chosen as outgroups: Rheum palmatum (NC_027728/ AY207370), R. wittrockii (NC_035950/ KF258686), Fagopyrum luojishanense (NC_037706), F. tataricum (NC_ 027161), and F. dibotrys (NC_037705/ JN235080).

\section{Supplementary information}

\section{Supplementary information accompanies this paper at https://doi.org/10.} 1186/s12870-020-02466-5.

Additional file 1: Table S1. List of genes in the chloroplast genome for 21 Calligonum species *Gene with intron (S).

Additional file 2: Figure S1. Sequence identity plots for 21 assembled Calligonum chloroplast. Genomes, with C. jeminaicum as reference (left). Special insertion (or deletion) test results (right). Segments I: about 800 bp, segments II: about 400 bp.

Additional file 3: Figure S2. Sequence identity plots for six Polygonaceae genera plastid genomes, with C. jeminaicum as a reference (left). Red boxes represent two special insertion (or deletion) segments I (about 800 bp) and II (about 400 bp).

Additional file 4: Table S2. Primers and samples for special insertion test.

Additional file 5: Figure S3. Genome rearrangement events of 21 assembled Calligonum species.

Additional file 6. Excel spreadsheet of the numbers of nucleotide substitutions and sequence distance in 32 complete cp genomes (Sheet1). The upper triangle shows the number of nucleotide substitutions and the lower triangle indicates the number of sequence distance in complete cp genomes.

Additional file 7: Figure S4. The $d N / d S(\omega)$ value of protein-coding genes from Calligonum plastid genomes.

Additional file 8: Figure S5. Three sections of Calligonum based on the flora of Iran (Rechinger \& Schiman-Czeika, 1986). The colors represent different sections. Numbers above branches indicate posterior probabilities (PP, left) and the ML bootstrap values (BS, right). Branches with* have $P P=1$ and $B S=100 \%$.

Additional file 9: Figure S6. Bayesian tree inferred from different corebarcodes of the Calligonum. Numbers above branches indicate posterior probabilities (A: ITS1 + 5.8S; B: $5.8 S$ + ITS2; C: matK; D: rbcL E: matK + rbcL; $\mathbf{F}: \operatorname{trnH}-p s b A ; \mathbf{G}:$ matK $+r b c L+t r n H-p s b A ; \mathbf{H}: m a t K+r b c L+t r n H-p s b A+I T S ;$ I: $\operatorname{trnE}-T ; \mathbf{J}: \operatorname{trn} T-L)$.

Additional file 10. Excel spreadsheet of the heterozygous sites and inter-individual polymorphic sites of nrlTS sequences. * represents the sequence from Genbank. $\Delta=$ CGGAGATC.

Additional file 11: Table S3. nrlTS sequence assembly information. Additional file 12: Table S4. Molecular models selected for all the dataset.

\section{Abbreviations}

AIC: Akaike Information Criterion; BI: Bayesian Inference; BS: Bootstrap; CTAB: Cetyltrimethyl ammonium bromide method; DnaSP: DNA Sequences Polymorphism; DOGMA: Dual Organellar Genome Annotator; IR: Inverted repeat; LSC: Large single copy; MCMC: Markov Chain Monte Carlo; ML: Maximum Likelihood; NCBI: National Center for Biotechnology Information; nrlTS: Nuclear ribosomal internal transcribed spacer; rRNA: Ribosomal RNA; SSC: Small single copy; tRNA: Transfer RNA

\section{Acknowledgements}

The authors thank Wei Shi and Qiu-mei Cao for their assistance in species identification. We also thank Yu-Ying Zhou, Nan Zhao, Yong Xu, Tian-Wen Xiao, Xun Yuan, and Lu Jin for their kind help in molecular experiments and data analysis. Prof. Lian-Ming Gao, Dr. Hai-Fei Yan, and Dr. Gang Yao provided suggestions during the manuscript preparation.

\section{Authors' contributions}

$X G$ and $Y F$ conceived and designed the research. $X G, Y F$ and $T L$ collected the leaf materials. FS and TL performed the experiments and analyzed the data. FS, TL drafted the manuscript. $K B, X G$ and $Y F$ revised the manuscript. All authors gave final approval of the paper. All authors read and approved the final manuscript.

\section{Funding}

This study was financially supported by National Natural Science Foundation of China (31770227), the National Basic Resource Survey of China (2017FY100201) and the Large-scale Scientific Facilities of the Chinese Academy of Sciences (2017-LSFGBOWS-01). The funding body provided funding to the research project, but played no role in the design of this study, collection, data analysis, and in the writing of this manuscript. These were the sole responsibilities of the authors.

\section{Availability of data and materials}

All complete plastid genome and nrlTS sequences used in this study are available from the National Center for Biotechnology Information (NCBI) (see Table 1). 


\section{Ethics approval and consent to participate}

Not applicable.

\section{Consent for publication}

Not applicable.

\section{Competing interests}

The authors declare that they have no competing interests.

\section{Author details}

'University of Chinese Academy of Sciences, Beijing 100049, China. ${ }^{2}$ State Key Laboratory of Desert and Oasis Ecology, Xinjiang Institute of Ecology and Geography, Chinese Academy of Sciences, Urumqi 83011, China. ${ }^{3}$ Key Laboratory of Plant Resources Conservation and Sustainable Utilization, South China Botanical Garden, Chinese Academy of Sciences, Guangzhou 510650, China. ${ }^{4}$ Department of Biology, Columbus State University, University System of Georgia, Columbus, GA 31907-5645, USA. ${ }^{5}$ The Specimen Museum of Xinjiang Institute of Ecology and Geography, Chinese Academy of Sciences, Urumgi 83011, China.

Received: 13 November 2019 Accepted: 26 May 2020

Published online: 08 June 2020

\section{References}

1. Liu YX. Flora in desertis reipublicae populorum sinarum, vol. 1. Beijing: Science Press; 1985. p. 307-16.

2. Mao ZM, Pan BR. The classification and distribution of the genus Calligonum L. in China. Acta Phytotaxonomica Sinica. 1986;24(2):98-107.

3. Bao B. Grabovskaya-Borodina AE. Calligonum L. In: Wu CY, Raven PH, editors. Flora of China, vol. 5. Beijing: Science Press (Beijing) and Missouri Botanical Garden Press (St. Louis); 2003. p. 324-8.

4. Mao ZM, Yang G, Wang CG. Studies on chromosome numbers and anatomy of young branches of Calligonum of Xinjiang in relation to the evolution of some species of the genus. Acta Phytotaxonomica Sinica. 1983; 21(1):44-9.

5. Soskov YD. The genus Calligonum L.: Taxonomy, distribution, evolution, introduction. Novosibirsk: Russian Academy of Agricultural Sciences; 2011. p. 359-61

6. Sanchez A, Schuster TM, Burke JM, Kron KA. Taxonomy of Polygonoideae (Polygonaceae): a new tribal classification. Taxon. 2011;60(1):151-60.

7. CBOL Plant Working Group, Hollingsworth PM, Forrest LL, Spouge JL, Hajibabaei M, Ratnasingham S, van der Bank M, Chase MW, Cowan RS, Erickson DL, et al. A DNA barcode for land plants. Proc Natl Acad Sci U S A. 2009;106(31):12794-7.

8. Liu J, Yan HF, Newmaster SG, Pei N, Ge XJ. The use of DNA barcoding as a tool for the conservation biogeography of subtropical forests in China. Divers Distrib. 2015;21(2):188-99.

9. China Plant BOL Group, Li DZ, Gao LM, Li HT, Wang H, Ge XJ, Liu JQ, Chen ZD, Zhou SL, Chen SL, et al. Comparative analysis of a large dataset indicates that internal transcribed spacer (ITS) should be incorporated into the core barcode for seed plants. Proc Natl Acad Sci U S A. 2011;108(49): 19641-6.

10. Sanchez A, Schuster Tanja M, Kathleen AK. A large-scale phylogeny of Polygonaceae based on molecular data. Int J Plant Sci. 2009;170(8):1044-55.

11. Sun YX, Zhang ML. Molecular phylogeny of tribe Atraphaxideae (Polygonaceae) evidenced from five cpDNA genes. J Arid Land. 2012;4(2): 180-90.

12. Li Y, Feng $Y$, Wang $X Y$, Liu B, LV GH. Failure of DNA barcoding in discriminating Calligonum species. Nord J Bot. 2014;32(4):511-7.

13. Shi W, Wen J, Zhao Y, Johnson G, Pan B. Reproductive biology and variation of nuclear ribosomal ITS and ETS sequences in the Calligonum mongolicum complex (Polygonaceae). PhytoKeys. 2017;76:71-88.

14. Parks M, Cronn R, Liston A. Increasing phylogenetic resolution at low taxonomic levels using massively parallel sequencing of chloroplast genomes. BMC Biol. 2009;7:84.

15. Li X, Yang Y, Henry RJ, Rossetto M, Wang Y, Chen S. Plant DNA barcoding: from gene to genome. Biol Rev. 2015;90(1):157-66.

16. Wang X, Gussarova G, Ruhsam M, de Vere N, Metherell C, Hollingsworth PM, Twyford AD. DNA barcoding a taxonomically complex hemiparasitic genus reveals deep divergence between ploidy levels but lack of species-level resolution. AoB Plants. 2018;10(3):ply026.
17. Tonti-Filippini J, Nevill PG, Dixon K, Small I. What can we do with 1000 plastid genomes? Plant J. 2017;90(4):808-18.

18. Coissac E, Hollingsworth PM, Lavergne S, Taberlet P. From barcodes to genomes: extending the concept of DNA barcoding. Mol Ecol. 2016;25(7): 1423-8.

19. Hollingsworth PM, Li DZ, van der Bank M, Twyford AD. Telling plant species apart with DNA: from barcodes to genomes. Philos Transact R Soc B Biol Sci. 2016;371(1702):20150338

20. Bruun-Lund S, Clement WL, Kjellberg F, Ronsted N. First plastid phylogenomic study reveals potential cyto-nuclear discordance in the evolutionary history of Ficus L. (Moraceae). Mol Phylogenet Evol. 2017;109: 93-104.

21. Du YP, Bi Y, Yang FP, Zhang MF, Chen XQ, Xue J, Zhang XH. Complete chloroplast genome sequences of Lilium: insights into evolutionary dynamics and phylogenetic analyses. Sci Rep. 2017:7(1):5751.

22. Manzanilla V, Kool A, Nguyen Nhat L, Nong Van H, Le Thi TH, de Boer HJ. Phylogenomics and barcoding of Panax: toward the identification of ginseng species. BMC Evol Biol. 2018;18(1):44.

23. Krawczyk K, Nobis M, Myszczynski K, Klichowska E, Sawicki J. Plastid superbarcodes as a tool for species discrimination in feather grasses (Poaceae: Stipa). Sci Rep. 2018:8(1):1924.

24. Fu CN, Wu CS, Ye LJ, Mo ZQ, Liu J, Chang YW, Li DZ, Chaw SM, Gao LM Prevalence of isomeric plastomes and effectiveness of plastome superbarcodes in yews (Taxus) worldwide. Sci Rep. 2019;9(1):2773.

25. Li W, Liu Y, Yang Y, Xie X, Lu Y, Yang Z, Jin X, Dong W, Suo Z. Interspecific chloroplast genome sequence diversity and genomic resources in Diospyros. BMC Plant Biol. 2018;18(1):210.

26. Liu L, Wang Y, He P, Li P, Lee J, Soltis DE, Fu C. Chloroplast genome analyses and genomic resource development for epilithic sister genera Oresitrophe and Mukdenia (Saxifragaceae), using genome skimming data. BMC Genomics. 2018;19(1):235.

27. Jiao $L$, Lu Y, He T, Li J, Yin Y. A strategy for developing high-resolution DNA barcodes for species discrimination of wood specimens using the complete chloroplast genome of three Pterocarpus species. Planta. 2019;250(1):95-104.

28. Kim HT, Kim JS, Lee YM, Mun J-H, Kim J-H. Molecular markers for phylogenetic applications derived from comparative plastome analysis of Prunus species. J Syst Evol. 2019;57(1):15-22.

29. Rechinger KH, Schiman-Czeika H. Polygonaceae. In: Flora Iranica, vol. 56. Graz: Verlag des Naturhistorischen Museums Wien; 1968. p. 36-46.

30. Wang $C L$, Ding MQ, Zou CY, Zhu XM, Tang Y, Zhou ML, Shao JR. Comparative analysis of four buckwheat species based on morphology and complete chloroplast genome sequences. Sci Rep. 2017;7:6514.

31. Gui $L$, Jiang $S$, Wang $H$, Nong $D$, Liu Y. Characterization of the complete chloroplast genome of sorrel (Rumex acetosa). Mitochondrial DNA Part B. 2018:3(2):902-4.

32. Luo X, Wang T, Hu H, Fan L, Wang Q, Hu Q. Characterization of the complete chloroplast genome of Oxyria sinensis. Conserv Genet Resour. 2016;9(1):47-50

33. Zhu A, Guo W, Gupta S, Fan W, Mower JP. Evolutionary dynamics of the plastid inverted repeat: the effects of expansion, contraction, and loss on substitution rates. New Phytol. 2016;209(4):1747-56.

34. Wen ZB, Yan L, Zhang HX, Meng HH, Ying F, Wei S. Species-level phylogeographical history of the endemic species Calligonum roborovskii and its close relatives in Calligonum section Medusa (Polygonaceae) in arid North-Western China. Bot J Linn Soc. 2016;180(4):542-53.

35. Feng $Y$, Pan BR, Shen GM. Revision of two species of Calligonum from the desert of Xinjiang, Northwestern China. J Arid Land. 2010;2(3):231-4.

36. Abdurahman M, Sabirhazi G, Liu B, Yin L, Pan B. Comparison of five Calligonum species in Tarim Basin based on morphological and molecular data. Exp Clin Sci J. 2012:11:776-82.

37. Xiang QP, Wei R, Shao YZ, Yang ZY, Wang XQ, Zhang XC. Phylogenetic relationships, possible ancient hybridization, and biogeographic history of Abies (Pinaceae) based on data from nuclear, plastid, and mitochondrial genomes. Mol Phylogenet Evol. 2015;82(Pt A):1-14.

38. Folk RA, Mandel JR, Freudenstein JV. Ancestral gene flow and parallel organellar genome capture result in extreme phylogenomic discord in a lineage of angiosperms. Syst Biol. 2017;66(3):320-37.

39. Chen J, Cannon $\mathrm{CH}_{1} \mathrm{Hu} \mathrm{H}$. Tropical botanical gardens: at the in situ ecosystem management frontier. Trends Plant Sci. 2009;14(11):584-9.

40. Fazekas AJ, Burgess KS, Kesanakurti PR, Graham SW, Newmaster SG, Husband BC, Percy DM, Hajibabaei M, Barrett SC. Multiple multilocus DNA 
barcodes from the plastid genome discriminate plant species equally well. PLoS One. 2008;3(7):e2802.

41. Tavakkoli S, Osaloo SK, Maassoumi AA. The phylogeny of Calligonum and Pteropyrum (Polygonaceae) based on nuclear ribosomal DNA ITS and chloroplast trnL-F sequences. Iran J Biotechnol. 2010;8(1):7-15.

42. Mabberley D. Mabberley's Plant-book: a portable dictionary of plants, Teir Classifcations, and uses. Cambridge: Cambridge University Press; 2008. p. 1021.

43. Hollingsworth PM. Refining the DNA barcode for land plants. Proc Natl Acad Sci U S A. 2011;108(49):19451-2.

44. Weitemier K, Straub SC, Fishbein M, Liston A. Intragenomic polymorphisms among high-copy loci: a genus-wide study of nuclear ribosomal DNA in Asclepias (Apocynaceae). PeerJ. 2015;3:e718.

45. Percy DM, Argus GW, Cronk QC, Fazekas AJ, Kesanakurti PR, Burgess KS, Husband BC, Newmaster SG, Barrett SC, Graham SW. Understanding the spectacular failure of DNA barcoding in willows (Salix): does this result from a trans-specific selective sweep? Mol Ecol. 2014;23(19):4737-56.

46. Zinger L, Philippe H. Coalescing molecular evolution and DNA barcoding. Mol Ecol. 2016;25(9):1908-10

47. Wang A, Gopurenko D, Wu H, Lepschi B. Evaluation of six candidate DNA barcode loci for identification of five important invasive grasses in eastern Australia. PLoS One. 2017;12(4):e0175338.

48. Collins RA, Cruickshank RH. The seven deadly sins of DNA barcoding. Mol Ecol Resour. 2013;13(6):969-75.

49. Spooner DM. DNA barcoding will frequently fail in complicated groups: an example in wild potatoes. Am J Bot. 2009;96(6):1177-89.

50. Chen J, Zhao J, Erickson DL, Xia N, Kress WJ. Testing DNA barcodes in closely related species of Curcuma (Zingiberaceae) from Myanmar and China. Mol Ecol Resour. 2015;15(2):337-48.

51. Yin K, Zhang Y, Li Y, Du FK. Different natural selection pressures on the atpF gene in evergreen sclerophyllous and deciduous oak species: evidence from comparative analysis of the complete chloroplast genome of Quercus aquifolioides with other oak species. Int J Mol Sci. 2018;19(4):1042.

52. Alsos IG, Coissac E, Merkel MKF, Lammers Y, Alberti A, Orvain C, Dossat C, Boyer F, Hollingsworth P, Parducci L et al. Towards plant barcode 2.0 and its application in environmental and ancient DNA studies In: Scientific abstracts from the 8th International Barcode of Life Conference. Genome. 2019;62(6): 350-1.

53. Maryamgul A, Gulnur S, Liu B, Yin L, Pan B. Taxonomy of two Calligonum species inferred from morphological and molecular data. Vegetos. 2012; 25(2):232-6.

54. Mao ZM, Calligonum L. In: Fl. Reip. pop. Sinicae. In., vol. 25. Beijing: Science Press; 1998. p. 126-8.

55. Doyle JJ, Doyle JL. A rapid DNA isolation procedure for small quantities of fresh leaf tissue. Phytochem Bull. 1987;19:11-5.

56. Bolger AM, Lohse M, Usadel B. Trimmomatic: a flexible trimmer for Illumina sequence data. Bioinformatics. 2014;30(15):2114-20.

57. Dierckxsens N, Mardulyn P, Smits G. NOVOPlasty: de novo assembly of organelle genomes from whole genome data. Nucleic Acids Res. 2017;45(4):e18.

58. Langmead B, Salzberg S. Fast gapped-read alignment with bowtie 2. Nat Methods. 2012;9:357-9.

59. Li H, Handsaker B, Wysoker A, Fennell T, Ruan J, Homer N, Marth G, Abecasis G, Durbin R, Subgroup GPDP. The sequence alignment/map format and SAMtools. Bioinformatics. 2009;25(16):2078-9.

60. Wyman SK, Jansen RK, Boore JL. Automatic annotation of organellar genomes with DOGMA. Bioinformatics. 2004;20(17):3252-5.

61. Tillich M, Lehwark P, Pellizzer T, Ulbricht-Jones ES, Fischer A, Bock R, Greiner S. GeSeq - versatile and accurate annotation of organelle genomes. Nucleic Acids Res. 2017:45(W1):W6-W11.

62. Ripma LA, Simpson MG, Hasenstab-Lehman K. Geneious! Simplified genome skimming methods for phylogenetic systematic studies: a case study in Oreocarya (Boraginaceae). Appl Plant Sci. 2014;2(12):1400062.

63. Lohse M, Drechsel O, Bock R. OrganellarGenomeDRAW (OGDRAW): a tool for the easy generation of high-quality custom graphical maps of plastid and mitochondrial genomes. Curr Genet. 2007;52(5-6):267-74.

64. Mayor C, Brudno M, Schwartz JR, Poliakov A, Rubin EM, Frazer KA, Pachter LS, Dubchak I. VISTA: visualizing global DNA sequence alignments of arbitrary length. Bioinformatics. 2000;16(11):1046-7.

65. Darling AE, Mau B, Perna NT. ProgressiveMauve: multiple genome alignment with gene gain, loss and rearrangement. PLoS One. 2010;5(6): e11147.
66. Rozas J, Ferrer-Mata A, JC S-DB, Guirao-Rico S, Librado P, Ramos-Onsins SE, Sãn-GA. DnaSP 6: DNA sequence polymorphism analysis of large datasets. Mol Biol Evol. 2017;34(12):3299-302.

67. Kumar S, Stecher G, Li M, Knyaz C, Tamura K. MEGA X: molecular evolutionary genetics analysis across computing platforms. Mol Biol Evol. 2018;35(6):1547-9.

68. Yang Z. PAML 4: phylogenetic analysis by maximum likelihood. Mol Biol Evol. 2007;24(8):1586-91.

69. Katoh K, Standley DM. MAFFT multiple sequence alignment software version 7: improvements in performance and usability. Mol Biol Evol. 2013; 30(4):772-80.

70. Darriba D, Taboada GL, Doallo R, Posada D. jModelTest 2: more models, new heuristics and parallel computing. Nat Methods. 2012;9(8):772.

71. Ronquist F, Huelsenbeck JP. MrBayes 3: Bayesian phylogenetic inference under mixed models. Bioinformatics. 2003;19(12):1572-4.

72. Stamatakis A. RAxML version 8: a tool for phylogenetic analysis and postanalysis of large phylogenies. Bioinformatics. 2014;30(9):1312-3.

\section{Publisher's Note}

Springer Nature remains neutral with regard to jurisdictional claims in published maps and institutional affiliations.

Ready to submit your research? Choose BMC and benefit from:

- fast, convenient online submission

- thorough peer review by experienced researchers in your field

- rapid publication on acceptance

- support for research data, including large and complex data types

- gold Open Access which fosters wider collaboration and increased citations

- maximum visibility for your research: over $100 \mathrm{M}$ website views per year

At BMC, research is always in progress.

Learn more biomedcentral.com/submissions 